\title{
Influence Of Post Covid Change In Consumer Behavior Of Millennials On Advertising Techniques And Practices
}

\author{
Prakriti Rashi ${ }^{1}$, Ankur Singh Bist ${ }^{2}$, Ari Asmawati ${ }^{3}$, Mukti Budiarto ${ }^{4}$, Wahyu Yustika \\ Prihastiwi ${ }^{5}$ \\ 1,2Graphic Era Hill University, Bhimtal Campus, India \\ ${ }_{3,4,5}$ University of Raharja, Indonesia \\ e-mail: Prakriti.rashi7@gmail.com ${ }^{1}$, ankur1990bist@gmail.com² ${ }^{2}$, ariasmawati@raharia.info ${ }^{3}$, \\ mukti@raharia.info $^{4}$, wahyuyustika@raharja.info ${ }^{5}$
}

Rashi, P. ., Ankur Singh Bist, Ari Asmawati, Mukti Budiarto, \& Yustika Prihastiwi, W. (2021). Influence Of Post Covid Change In Consumer Behaviour Of Millennials On Advertising Techniques And Practices. Aptisi Transactions on Technopreneurship (ATT), 3(2), 87-94. https://doi.org/10.34306/att.v3i2.210

DOI: https://doi.org/10.34306/att.v3i2.210

\begin{abstract}
The pandemic caused by Covid 19 has kicked off survival strategies from vulnerable groups of people to small businesses, which has challenged the core operating practices and modified consumption patterns. Thus, effective marketing strategies are imperative in these times, that not only convey values of the brand but also resonate with people. Market disruptions are most likely to impact millennials and Gen Z and given the exploration and spending propensity, millennials are most likely to drive demand during the pandemic as well as in the post pandemic world. This research proposal aims to explore how consumer habits have changed during pandemic, how likely these habits will stick in the post pandemic world and how advertising needs to be transformed which relates best with millennials. The methodology involves a detailed analysis of literature and gathering insights from social media sites through big data. This research investigates the impact of avoiding deterministic automatisms purchasing processes, implying the need to understand, from an academic and conceptual standpoint, the utility of the set of business strategies to truly influence consumer purchasing behavior of Millennials.
\end{abstract}

Keywords: Covid, Millennials, Advertising.

\section{Background}

Coronavirus has ushered the entire world into a new normal filled with masks, sanitisers, $6 \mathrm{ft}$ social distancing norms and lockdowns, thus changing every sphere of life. Being a multifaceted crisis COVID -19 has impacted public health infrastructure and created a ripple effect across entire human society and the entire economic system. There have been various epidemic outbreaks such as MERS, Ebola, SARS, swine flu. Zika virus during the modern era but COVID - 19 pandemic is truly an unprecedented situation which has impacted all elements of human society. The ripple effect of public health guidelines and lockdowns led to economic instabilities, with many essential workers living paycheck to paycheck, relying on stimulus bonuses, large scale migration and closure of public places and tourism activities. Disruption in daily life led to transformation in spending and consumption patterns of consumers. This is a perfect opportunity to start again and reconnect and recalibrate the 
current conscious young generation to novel principles rooted in classical practices. For example, following the SARS outbreak in 2002, China's e-commerce industry grew 5 times. In the wake of recession during 2008-09, Dominoes aggressively targeted young consumers through Pizza recipe campaigns and pioneered digital trackers for delivery with an aim of engaging with the younger generation. This strategy helped it gain market share not only during the economic downturn but also during the recovery period.

\subsection{Changing Habits And Consumption Patterns Of Millennials}

Thanks to high speed internet and smartphone penetration, the e-commerce industry has grown all over the world and is expected to grow to US $\$ 200$ billion by 2026 in India. Digital platforms have been responsible for business continuity for essential as well as non essential purchases and continue to become a popular choice for Millennials as it provides convenience, value and availability and has gained consumer confidence during lockdowns and increased social distancing practices. With a new twist that includes healthcare, mental wellbeing, customers have been impacted financially. It may provide a new incentive for long-term lifestyle changes, implying a growing business of transitioned customers who will become more thrifty as a result of a new value of "save it and hoard" and a change in their purchasing patterns [1].

Marketers must pay attention to the evident increase in people adopting either a thrifty or very simple lifestyle by incentivising shoppers to spend only what they truly require rather than overbuying, taking into consideration that this is not a form of poverty or choosing a difficult life, but rather responsible purchasing. As far as future implications are concerned overall spending and especially, online spending at food retailers is expected to increase by millennial consumers in the coming decade. Marketers need to evaluate the future of in-store and point of purchase advertising as it will determine how advertising budget is allocated effectively.

\subsection{Changing Media Habits}

Before the onset of COVID - 19 pandemic, millennials have been regarded as a generation focussed more on spending rather than saving, however layoffs, salary cuts and looming uncertainty regarding the future have altered the spending behavior. To determine the course of action and advertising strategies in a post covid it is necessary to ascertain if the habits and patterns observed during the pandemic will be continued or abandoned by the consumers. Media consumption of millennials has increased during the pandemic because the majority of people were confined to their sofas, however this consumption is different across generations and is very likely to change in the post pandemic world [2] [3]. Trend was gradually shifting towards streaming video platforms even before the pandemic. But due to Covid - 19 and stay at home orders have amplified the atmosphere for subscriptions and streaming online content. Households can switch from shared media consumption to personal consumption as each member requires devices for their own particular purpose. As children require tablets or smartphones for attending virtual classes. GenX and millennials are bound by working requirements to continue the use of digital services and devices. Thus, Coronavirus has altered the objectives of streaming online content. Pre-pandemic consumption was justified by unwinding being the main reasons and distraction after a day of work, whereas during pandemic anxiety and stress turned out to be a major reason [4].

Pandemic has made people more likely to purchase subscription OTT services as they were in isolation or quarantine or away from friends and family and loved ones. Almost one-third of Gen Zers purchased Netflix. Every generation whether GenX, Millennials or GenZ had to rely on their smartphones and laptops to stay informed regarding the developments and 
spread of the virus as well as distract themselves. This has created opportunities for content creators, Media and advertising companies for engaging audiences [5]. As far as sustainability of patterns of media consumption observed during the pandemic is concerned, Gen $Z$ and millennials can marginally keep up the increase in the time spent on digital media, in such a case online video streaming and gaming platforms like Steam and gaming companies can experience high gains and increased user base in a post pandemic world as well. A correction in behavior of consumers for use of social media is also expected, it is important to determine whether the numbers will become closer to their pre-pandemic levels, or this increase in consumption could continue. As a lot of folks increased their social media usage throughout the pandemic, they additionally appear to be more willing to have interaction with social ads. The behavioral amendment is often attributed to the growing need to connect with others during difficult times.

The second transformation is the reduction in the value of pay TV in comparison with video streaming transmission services that facilitate advertising. Over the past ten years, Pay TV has experienced a decrease in viewing hours across almost every demographic and the ubiquitous adoption of smartphones and tablets make it less probable that viewers devote attention to adverts on television. As a result there has been an increase in costs associated with adverts on television. A fraction of TV viewing has moved to different distribution platforms, such as Over-the-top (OTT) providers [6]. Over the past years, Investment in OTT platforms has accelerated at an unprecedented pace. Many big players in the media industry have continued this trend even during the pandemic because consumers have a growing preference for D2C content [7]. Even with such contradictory trends TV style advertising possesses potential for ad-supported streaming video service platforms such as Youtube. And now due to COVID - 19, dependence on digital platforms has grown phenomenally during COVID-19 pandemic, Zoom a video calling platform, recorded a $418 \%$ increase in adoption rates, as people had to rely on virtual business meetings, virtual classrooms and virtual socializing events to reduce the spread of coronavirus. With country wide lockdowns all over the world, e-commerce retail sales increased from $16 \%$ to $27 \%$ in the US and to $30 \%$ in the UK [8].

\subsection{Increased Inclination Towards Sustainable Practices}

Numerous corporations have thrived for decades—and prospered financially-despite having no purpose that is directly linked to public benefit. Nonetheless, two worldwide trends show that firms might do more than "well" by ensuring that their company mission and subsequent CSR programmes are focused on improving the world. With the use of their products and services, marketers can raise awareness among large population bases for making changes towards organic living [9] [10].

The world is turning to social enterprises, which have a mission that integrates profit with societal contribution. Companies are moving in this direction, with CEOs citing "impact on society, including income inequality, diversity, and the environment" as their most significant success metric [11]. Companies that share their beliefs are more likely to be supported, whereas those that do not hold themselves accountable to these values are less likely to be supported [12].

Businesses are now being turned to for solutions around the world: People believe companies are more able than organizations and governments to handle global crises, as per Edelman Trust Barometer, which polled 34,000 people in 28 countries. Stakeholders such as social groups, shoppers, and employees, are critical to an organization's success in the long 
run (only 13 percent stated shareholders as the most important stakeholder). Consumers are drawn toward businesses that support socially relevant efforts, and "brand" is increasingly representing how people see the company. To effectively respond to the call of stakeholders, firms should infuse a societal component to purpose throughout the enterprise.

\subsection{Need Of The Hour}

Marketers need to amplify the inclusion of advertising with digital and social platforms that have potential of high reach and engagement with young demographics, that allow brands to cultivate brand-consumer interactions organically, allow for storytelling, share brand experience through friends or trusted influencers. Emotional appeals influence people's attitudes towards the ad. Marketers know that positive emotions pose less of a risk in brand communication than negative emotions. Marketers should rethink their language and communications strategy to effectively communicate their brand's values and value offer to customers in today's environment. Effective businesses will be able to perceive and relate to the tremendous emotions that young consumers are experiencing [13] [14].

As outlined above,many advertisers rely on direct response marketing for revenue generation. In the long run, this might enhance the trajectory of digital platforms in double ways. Initially, digital marketing appears to be experiencing less reduction in allocation of budget, and more responses [15] from consumers and viewers relative to others in the ecosystem, enabling digital media to emerge faster and stronger during the crisis. Also, digital media contains behavioural responses and data of consumers during the pandemic. Digital media helps companies understand the psychology behind buying decisions of consumers and gain competitive advantage. The internet world provides limitless opportunities to increase touch points with young consumers on their own territory, digitise new aspects of the customer journey, and create novel brand engagements. Advertisers and marketers should choose their own branded channels and tools to implement changes. These although will not be enough on their own [16],

To address the disparities in epidemic impact, government legislation, and consequent consumer behaviour across markets, developing high-frequency demand-sensing technologies and a location - based approach to marketing will be critical [17] [18] [19]. Experimentation and incrementality-based ways to evaluate marketing performance will also be utilised. in a world where the past can't always determine the market, recent attributions can't keep up with the high complexity of the digital transformation journey. These competencies will be crucial in the short run and will continue to provide marketers with a strategic edge even after the current scenario has passed. Other industry experts, mirroring this viewpoint, advocate embracing digital transformation. In this context, digital advertising does not replace outdoor advertising [20]; rather, it is a refinement of the format. Advertisers may welcome the movement by emphasizing on audiences and using data-intensive behavioral insights and information to discover and target the right customers in more cost-effective and efficient ways [21]. This was already a driving force in the out of house advertising segment before the pandemic. In other terms, the post-COVID prospect of out of house, as per some, is Digital out of the house marketing.

\subsection{Potential Of Digital Marketing}

Mahindra Tractors relied on search engine optimisation, digital advertisements and profiles on social media to reach its target audience online. Mahindra tractors targeted the large chunk of population which had migrated from urban to rural areas during the first wave of strict lockdowns all over India and planned to reside in their hometowns for at least a year [22]. 
Mahindra tractors generated media buzz through social media campaigns and offered coupons and discounts to capture the prospective buyers looking for tractors. In this way, Mahindra tractors managed to capture a significant fraction of market share, reach customers in rural areas having internet connectivity, build emotional connection with farmers in times of need and clear out their inventory during a time when industry was facing a contraction in sales [23].

While restaurant chains and franchises can afford to lose a percentage of revenue through reduced dine - in services, small restaurants rely heavily on the day to day revenue from customers who dine in. With increased restrictions, ubereats, zomato, swiggy witnessed a rise in the number of small restaurants joining their platforms to stay afloat during the pandemic. Thus, small players could compete with the big sharks and customers could benefit from the coupons. Zomato promoted its campaign rigorously on youtube, OTT advertisements and social media platforms. Advertisements having emotional appeals, brands sharing their safety protocols and standard of operating procedures, garnered a higher number of likes and shares on social media and gained trust of customers. Uber Eats positioned itself as "Your go to restaurant at the comfort of your home", dettol launched a "hand washing campaign" in its advertisements, appealing the viewers to maintain social distance, sanitize hands, and wear masks.

Covid-19 pandemic has challenged the normal perceived way of living. Urging businesses to be agile and adaptable to the changes taking place at an unprecedented pace. Management not only had to rely heavily on digital infrastructure, but support employees for prolonged uncertainty and focus on creating a productive business environment from the comfort of their homes.

Digital Marketing has its pros in terms of accurate results and reach through click through rates, and analyzing data to understand consumer sentiment. Paid media through click through rates observed an increase in investment in the advertising budget allocation. Instagram and the influencer culture showcases potential in terms of reaching out to Gen Z and the Millenials as Instagram has one of the fastest growing subscriber base, dedicated platform for shopping and paid advertisements schemes for the targeted customers.

\section{Literature Review}

\section{Consumer sentiment and behavior continue to reflect the uncertainty of the COVID-19 crisis - McKinsey (2020)}

As per the Mckinsey report wherein they surveyed consumers from all over the world, to ascertain the impact of Covd - 19 crisis on the psychology and sentiments, the crisis has disrupted normal consumer behavior and consumers all over the world have responded by exhibiting different buying patterns with a resolution for incorporating these behaviors in a post pandemic world. Countries such as Germany and Japan act as anomalies as these countries experienced a moderate degree of economic disruption and recession period. A further development in the buying behavior of consumers is support for local businesses and holistic purpose of the purchase, while quality and quality continue to be top driving forces and important considerations when it comes to choosing new places to shop or new brands. Initially Covid - 19 pandemic diverged the spending purposes to essential purposes while leisure took a back seat. But after ease in restrictions, consumers in India and China started diversifying their expenditures into categories other than household essentials and groceries. Especially in India, Consumers quoted festivities and wedding season as a major reason for spending across various other purposes. This implies that policy intervention and restrictions influences how consumers decide their expenditure outlay.

TATA Capital - Millennial Pivot report (2019) 
Forty percent of millennials aim to start saving and prepare for economic uncertainties. The study describes this change in attitude as "Millennial Pivot", that is change in behavior observed after the age of 25 , while marketers might consider Millennials young, their way of spending and brand interaction is different from GenZ cohort. The study showcases that $34 \%$ of the Gen Zers allocate $15 \%$ of their total budget on non-essentials while in the case of millennials it was only $31 \%$ allocating $15 \%$ of the total budget on non-essentials. However, such patterns might experience a change, as millennials have experienced a significant reduction in their income due to pandemic induced layoffs and pay cuts. Millennials are also anticipated to spend less at restaurants and more at off-premises, with fast-food eateries performing better than traditional restaurants in digital as well as in-house dining. The rapid increase observed in Carryout, drive-through orders, online ordering, and delivery apps are projected to return to pre-COVID-19 levels.

\section{Research Objectives}

Towards this purpose, the following study questions have been formulated in order to anticipate change in consumer behavior due to coronavirus in a post pandemic world and the subsequent need of change in advertising strategies.

Research Question 1 - How consumer behavior particularly of millennials, has evolved in response to the pandemic caused by the novel coronavirus

Research Question 2 - What has been the influence of advertising strategies adopted during the pandemic on the consumer behavior and consumption pattern of millennials

Research Question 3 - What are the future implications and scope of such advertising strategies.

\subsection{Research Design And Method}

To examine the changes in the advertising ecosystem during the Corona 19 outbreak, and leverage the wisdom and insight, the research strategy for this study includes related literature review, psychometric tests and detailed social media data analysis through big data approach.

\subsection{Preliminary Suppositions And Implications}

The significance of change in modern consumption of Millennials is extremely important to be understood and researched by marketing researchers. This article serves as a beginning point for understanding customer feelings or requirements in purchasing in a post Covid - 19 setting, as well as how they might be used to ensure effective advertising practices and techniques. Other characteristics such as learning from crises, simplicity, changing requirements, psychology, geography, culture, thrifty behavior, and age could all be explored as potential correlations of this compelled consumer behavior. Changes in the media advertising ecosystem and communication should be predicted and addressed by the advertising market and experts. When addressing consumers who are diverse in terms of geography, gender, and generation, a differentiated approach for executing effective social advertising is also essential, highlighting the strategic relevance of fine-tuning demand segmentation methods. The pandemic "turned everything upside down." Branding communications used to be a constant, and advertisers seeked opportunities in technology. Previously, technology served as a differentiator. The attention has moved. The cornerstone will now be marketing innovation, data, insights, and ad savvy tech. The expectation that brands deliver their products and services in ways that fulfill customer requirements is a result of the epidemic and the transition in how customers shop. Those who do not follow through will be left behind. That means a faster shift toward direct-to-consumer sales, which isn't just for nascent brands anymore. To reinforce or renew brand loyalty, the optimal customer experience is crucial. Consumers were not able to purchase their preferred brands due to business closings, product scarcity, supply chain bottlenecks and household budgetary restraints throughout the previous year. Every big disruption we've observed in the past has 
resulted in a reshuffle of brands. Even in regular times, when major changes occur in ordinary households, the brand loyalty deck is flipped. In terms of organizational implications, the study suggests that business managers should strive to improve the overall customer experience by focusing at all stages of business beginning with problem identification and moving through information search, alternative evaluation, purchase, and post-purchase. Managers can choose the most effective way of advertising that allows potential buyers to imbibe the information they need to optimize their buying decision, such as ratings, comments from buddies or specialists, or influencers, promote the use of e-commerce platforms, and gather feedback on post-purchase behavior. Managers can choose the most effective way of advertising that allows potential buyers to imbibe the information they need to optimize their buying decision, such as ratings, comments from buddies or specialists, or influencers, promote the use of e-commerce platforms, and gather feedback on post-purchase behavior.

\section{References}

[1] Dodson, I. (2016). The art of digital marketing: the definitive guide to creating strategic, targeted, and measurable online campaigns. John Wiley \& Sons.

[2] Hanlon, A. (2019). Digital marketing: strategic planning \& integration. Sage.

[3] Chaffey, D., \& Smith, P. R. (2017). Digital marketing excellence: planning, optimizing and integrating online marketing. Routledge.

[4] Abe, S. (2020). Market trends and D2C opportunities in the COVID-19 landscape. The AdRoll Blog.

[5] Accenture. (2020). How COVID-19 will permanently change consumer behaviour.

[6] Koslow, L., Lee, J., Bharadwaj, A., Sanghi, K., \& Jain, N. (2020). COVID-19 consumer sentiment snapshot: Fighting in the dark. Retrieved January, 3, 2021.

[7] Deloitte, P. (2020). Impact of COVID-19 on consumer business in India.

[8] KPMG. (2020). Potential Impact of COVID-19 on the Indian Economy.

[9] Mehta, S., Saxena, T., \& Purohit, N. (2020). The new consumer behaviour paradigm amid COVID-19: Permanent or transient?. Journal of Health Management, 22(2), 291-301.

[10] Sheth, J. N., Sethia, N. K., \& Srinivas, S. (2011). Mindful consumption: a customer-centric approach to sustainability. Journal of the academy of marketing science, 39(1), 21-39.

[11] Covid19 media consumption generation pandemic entertainmen https://www.weforum.org/agenda/2020/04/covid19-media-consumption-generation-pan demic-entertainment/

[12] Marketing to gen $z$ during covid-1 https://www.voguebusiness.com/ consumers/marketing-to-gen-z-during-covid-19.

[13] The covid 19 epidemic fear and greed in marketing https://medium.com/the-covid-19-epidemic-fear-and-greed-in-marketing/the-covid-19-e pidemic-fear-and-greed-in-marketing-consumption-a9a44072fa07.

[14] Audience and brand building to attract millennial audiences https://www.similarweb.com/corp/blog/research/audience-and-brand-building/attract-mil lennial-audiences/

[15] New rules millennial marketing 2021 https://www.cmo.com.au/article/686123/new-rules-millennial-marketing-2021/https://ww w.tandfonline.com/doi/full/10.1080/10641734.2021.1876797?src=recsy

[16] Wheaton, M. G., Prikhidko, A., \& Messner, G. R. (2021). Is fear of COVID-19 contagious? The effects of emotion contagion and social media use on anxiety in response to the coronavirus pandemic. Frontiers in psychology, 11, 3594.

[17] Inspiring back to normal ads campaigns by brands https://digitalagencynetwork.com/inspiring-back-to-the-new-normal-ad-campaigns-by-b rands-for-the-post-covid-19-era/

[18] Gangadharbatla, H. (2008). Facebook me: Collective self-esteem, need to belong, and 
internet self-efficacy as predictors of the iGeneration's attitudes toward social networking sites. Journal of interactive advertising, 8(2), 5-15.

[19] Gangadharbatla, H. (2019). Social media and advertising theory. In Advertising theory (pp. 363-381). Routledge.

[20] Lang, A. (2013). Discipline in crisis? The shifting paradigm of mass communication research. Communication Theory, 23(1), 10-24.

[21] Malthouse, E. C., \& Li, H. (2017). Opportunities for and pitfalls of using big data in advertising research. Journal of Advertising, 46(2), 227-235.

[22] His name is, AP, Cloud, IU, Disso, JP, \& Younas, M. (2019). Similarity hash based scoring of portable executable files for efficient malware detection in loT. Future Generation Computer Systems.

[23] Nosouhi, MR, Yu, S., Zhou, W., Grobler, M., \& Keshtiar, H. (2020). Blockchain for secure location verification. Journal of Parallel and Distributed Computing, 136, 40-51. 